\title{
Mulheres ilhadas: representações do feminismo entre jovens mulheres universitárias em Belo Horizonte
}

\author{
Antony Henrique Tomaz Diniz*
}

\begin{abstract}
Resumo: Este artigo procura identificar quais as representações sociais que as alunas universitárias da PUC - MG têm sobre o feminismo, em suas mais variadas vertentes e, em que medida essas representações colocam aproximações e distanciamentos em relação aos movimentos feministas e suas pautas reivindicatórias. Com base nas teorias críticas feministas, discuto como as representações com relação ao feminismo podem constituir abismos ou pontes para aproximação com movimentos sociais que tiveram grande influência na academia, mas que cada vez mais vêm carregando rótulos que lhes afastam das próprias mulheres.
\end{abstract}

Palavras-chave: feminismo, academia, imaginário social.

\section{Introdução}

Trazer os debates feministas para dentro dos círculos acadêmicos, desde a década de 60 do século XX, tem sido bastante profícuo para a academia, contribuindo para gerações de pensadoras e militantes preocupadas com as condições de vida das mulheres em todo o mundo. A universidade, como espaço de produção de conhecimento e melhoria da vida humana, tem se colocado ao lado dessas discussões políticas sobre o que é a condição feminina - em diferentes contextos e atravessada por questões como raça, classe, gerações, orientações sexuais, etc. - e analisado de maneira contundente a posição desse gênero em relação ao mundo social, marcadamente masculino e hostil às mulheres. Feministas de vários lugares agem como catalisadoras de profundas rupturas epistemológicas e teóricas, não só nas ciências humanas com sua produção crítica e política, mas como grandes motores do progresso das ciências.

\section{Aspectos metodológicos}

Este artigo é fruto de um estudo exploratório qualitativo, realizado em novembro de 2010, no Campus da Pontifícia Universidade Católica de Minas Gerais

${ }^{*}$ Graduando em Ciências Sociais - PUC-MG. 
(PUC-MG), com quatro mulheres, entre 18 e 23 anos, moradoras de Belo Horizonte, Minas Gerais ${ }^{1}$.

O método qualitativo foi escolhido, não só porque o tema abordado assim o exigia - na esteira do que Flick (2002) chama a atenção, de que alguns temas são mais bem abordados e trabalhados sob uma perspectiva qualitativa - mas também porque o catalisador da pesquisa foi a necessidade de testar os conhecimentos e as técnicas discutidos na disciplina de Métodos Qualitativos II, do curso de Ciências Sociais da PUC-MG no qual me matriculei. A metodologia qualitativa é a melhor forma de captar representações coletivas ${ }^{2}$ e individuais dos sujeitos e, portanto, é o caminho que me leva às definições sobre o feminismo que essas mulheres carregam.

O ponto de partida foi entender como as mulheres universitárias veem o feminismo e como se posicionam se valendo da visão que têm sobre as feministas e suas lutas. Além de compreender a proximidade das mulheres universitárias com o discurso e a luta feminista, onde elas se situam dentro desse quadro de pautas e questões levantadas pelas feministas, é preciso estender a análise para a posição de uma universidade particular e católica, lembrando que um dos primeiros grupos de estudos feministas ou de mulheres fundados no Brasil foi na PUC-SP, na década de 80, por Fanny Tabak; o Núcleo de Estudos sobre a Mulher³. Logo, é importante para mim, verificar o imaginário que esse grupo traz sobre as feministas e sua causa, e se esse imaginário coloca uma aproximação ou um distanciamento com os discursos feministas. Não se trata de classificá-las como feministas ou antifeministas, mas, antes de tudo, gostaria de conhecer as restrições e aproximações entre os grupos.

Creio que qualquer luta política pelos direitos das mulheres, que pontue a consciência da opressão do patriarcado contra elas e as reivindicações de benefí-

\footnotetext{
1 Ver o roteiro de entrevistas no Anexo ao final deste artigo.

${ }^{2}$ Conforme Horochovski (2004), entendo representações sociais como conceito e categoria analítica dentro das ciências sociais e da psicologia social que permitem mapear sentidos, imagens e construções psicossociais dos indivíduos sobre a realidade em que estão imersos e que motivam sua participação no mundo social, conformando inclusive as características dessa participação.

${ }^{3}$ Essa informação encontra-se em Maria Margareth Lopes, professora livre-docente no Instituto de Geociências e coordenadora do Núcleo de Estudos de Gênero - Pagu da UniCAMP, em seu texto de 2002, As grandes ausentes das inovações em Ciência e Tecnologia.
} 
cios e direitos a todos e a todas (militantes ou não; mulheres ou não), de alguma forma, se encontrará ligada à universidade. Isso se compreendermos a universidade como espaço de produção de conhecimento e reflexividade sobre nosso tempo, não podendo, portanto, ficar distanciada das demandas políticas das jovens mulheres universitárias e de qualquer outro grupo politicamente organizado e comprometido com direitos humanos e sociais. E o que me parece atual é justamente esse distanciamento, seja por posturas pós-estruturalistas que condenam a adesão a rótulos, discursos e identidades políticas e suas limitações, seja pela falta de politização e ignorância do significado dos movimentos sociais como agentes de mudanças necessárias nas dinâmicas sociais modernas, assim como as tentações de um conhecimento mais utilitarista. Meu trabalho busca identificar a dimensão desse distanciamento e, para além de entender o alcance dos discursos feministas, traçar um imaginário sobre essas mulheres, ora vistas como heroínas, ora vistas como fanáticas, mas sempre marcantes para o conhecimento acadêmico e para a vida das mulheres em geral.

\section{O feminismo e a universidade: imaginário e preconceito}

Antes de falar sobre as feministas na universidade, cumpre esclarecer que o feminismo está marcado, como muitos outros temas na modernidade (ou pósmodernidade), pelo plural. Dentro do feminismo, coabitam diversos feminismos. Assim como é amplo o mundo das mulheres, suas biografias e as consequências das opressões são múltiplas. Logo, em muitas passagens deste texto, se falará em feminismo, mas com a clareza de que se trata de um paradigma de atuação política que não se fecha em uma só possibilidade. Trata-se de reconhecer uma trajetória historicamente marcada em torno de construções e debates políticos sobre a natureza das dominações masculinas e as formas de opressão dos femininos. Anterior ao próprio debate sobre essas opressões encontra-se a compreensão de que não se trata de falar e lutar pela dignidade da mulher, mas sim das mulheres, visto que são muitas as possibilidades de encontrá-las.

Como ressaltado no livro Uma História do Feminismo no Brasil, de 2003, de Célia Pinto, são múltiplos os objetivos, as manifestações e as pretensões do femi- 
nismo, ainda mais no caso brasileiro. Dividido em "ondas", ou períodos históricos, o feminismo seria marcado por duas tendências: uma sufragista, bem comportada, que, ao invés de questionar as opressões às quais as mulheres estão sujeitas, acaba por se concentrar em uma busca pela cidadania e garantia de direitos políticos e sociais, mas sem a contestação da ordem patriarcal, e sim, uma espécie de inclusão dentro dessa ordem. A segunda tendência seria marcada por dois momentos, que a autora chama de mal comportados, quais sejam: o feminismo marcado pela influência marxista e anarquista e, portanto, que se alia à luta contra o capitalismo e contra a apropriação dos recursos materiais e simbólicos dos homens burgueses sobre as mulheres no patriarcado-capitalista; e o feminismo marcado pelos movimentos sociais das minorias sexuais e raciais, que problematizam a bipolaridade masculino/feminino, a sua complicada relação com os direitos sexuais e as performatividades de gênero, as orientações sexuais e as especificidades das mulheres negras (ОTто, 2004).

\begin{abstract}
A origem branca e ocidental do feminismo estabeleceu sua hegemonia na equação das diferenças de gênero e tem determinado que as mulheres não brancas e pobres, de todas as partes do mundo, lutem para integrar em seu ideário as especificidades raciais, étnicas, culturais, religiosas e de classe social (CARNEIRo, 2001, p. 4).

O debate era centrado nas relações heterossexuais. Isso indicava a dificuldade de lidar com a diversidade em relação à sexualidade no interior do movimento feminista, mas também, o desconhecimento ou o não reconhecimento das experiências das lésbicas em coletivos ou comunidades. [...] Esse debate aparece no movimento de mulheres justamente a partir da organização de coletivos lésbicos que questionaram o fato de se considerarem as relações heterossexuais como as únicas normais, e denunciaram esse fato como imposição da heterossexualidade a todas as mulheres. Esse questionamento trazia críticas às limitações do feminismo e à dificuldade de considerar a diversidade das experiências das mulheres [...] permanece havendo uma questão política a ser trabalhada em todos os espaços: a importância de construir uma perspectiva feminista de defesa da autonomia e da liberdade das mulheres. Ter uma política expansionista em uma sociedade ainda patriarcal e homofóbica [...] pressupõe combater todos os perigos em relação à sexualidade e, ao mesmo tempo, defender o direito à expressão do desejo feminino (FARIA, 2007, p. 2).
\end{abstract}

Desde as reivindicações moderadas e liberais das sufragistas brancas e europeias até as feministas marxistas com suas explicações materialistas para as opressões - marcadas por forte teor economicista e histórico - , passando pelas contribuições que as feministas negras e as militantes dos movimentos lésbicos trouxeram para o reconhecimento do forte caráter simbólico e sistêmico dessas opres- 
sões e as sutilezas das interseccionalidades envolvidas nessa questão, aquilo que se convencionou chamar de feminismo é hoje uma miríade de lutas e organizações políticas nas suas mais variadas formas, com pautas construídas e desconstruídas, que em certos momentos convergem, mas, em grande medida, são reflexo de especificidades geradas histórica, geográfica e politicamente.

Não parto de uma vertente única do feminismo, nem construí um feminismo que possa ser explicitado claramente. 0 que chamo de feminismo seria a adesão às lutas pelo avanço de algumas pautas políticas em que acredito serem as de maior expressividade no contexto belo-horizontino. As pautas selecionadas foram elencadas com base no meu conhecimento das demandas políticas com as quais tenho contato, graças à minha aproximação com alguns grupos de militantes feministas em Belo Horizonte, como as mulheres do movimento lésbico (ALEM - BH) e as da Marcha Mundial das Mulheres, sabendo da dificuldade que elas têm de encontrarem novas militantes ${ }^{4}$.

Historicamente, os feminismos têm sofrido uma série de ataques vindos das mais diferentes frentes. No senso comum, como afiança Zanetti (2008), a igualdade entre os sexos já foi alcançada, e as feministas são, muitas vezes, retratadas como mulheres histéricas, histriônicas, desprovidas de feminilidade e com posicionamentos bastante radicais. Isso está em desacordo com a maior parte das autoras que discutem sobre as atuais configurações dos feminismos materializados como movimentos sociais. Todas elas, entretanto, ressaltam que a participação de jovens universitárias na militância feminista e na criação de grupos de estudo de gênero tem caído drasticamente desde a década de 80.

\begin{abstract}
Nos anos de 1990, o feminismo sofreu um certo retraimento, que teve como uma de suas características a falta de renovação do movimento, marcada pelo raro ingresso de jovens militantes. Aparentemente não houve interesse das jovens em se aproximar do movimento, tão pouco parece ter havido uma preocupação das feministas, pelo menos que se revertesse em algum tipo de ação, de conquistar as novas gerações (ZANETTI, 2008, p. 3).
\end{abstract}

A maior parte das mulheres jovens, na universidade, veem o feminismo como uma sombra de algo do passado, que hoje está desatualizado e ligado a extre-

\footnotetext{
${ }^{4}$ Obtive essa informação graças ao contato que mantenho com algumas delas.
} 
mismos que elas evitam. As fontes das críticas são inúmeras e vêm de todos os lados, desde a esquerda marxista que compreende a luta feminista como apenas um lado da luta de classes, até os pós-estruturalistas que situam o feminismo como um apego a identidades que hoje estariam "líquidas" e não mais explicariam a realidade num contexto de complexificação e fluidez da vida moderna.

Por outro lado, apesar das jovens de hoje reconhecerem que muitos dos direitos que gozam atualmente são frutos da luta das feministas em outras décadas, também parecem não ter se interessado pelo movimento. Pode ter contribuído para isto a falsa idéia prevalecente na sociedade brasileira de que os direitos das mulheres foram todos conquistados por ocasião da Constituição de 1988, tornando-se, desta forma, desnecessária a continuidade do movimento (ZANETTI, 2008, p. 4).

A atuação feminista é representada na vida social como uma proposta de engajamento político muitas vezes radicalizada e cheia de estigmas que impedem a identificação de novas militantes. É o que estagnou e gerou esse enorme hiato entre vida militante e vida acadêmica.

Outra possibilidade é que as jovens tenham acreditado nas representações vigentes no senso comum, que apresentam o feminismo como "o machismo ao contrário", isto é, um movimento que pretende que as mulheres sejam as opressoras dos homens e não uma luta por igualdade de direitos; ou então, como um movimento formado por mulheres mal-amadas, histéricas, feias e/ou homossexuais, características às quais elas não querem ser associadas.

Estas representações sobre o feminismo e suas militantes, compartilhadas não só pelas jovens, mas também por boa parte da população, foi construída ao longo da história, com participação de vários setores da sociedade, inclusive de alguns considerados progressistas (ZANETTI, 2008, p. 4-5).

Para mim, esse é um dos grandes desafios para a continuidade dos movimentos feministas, sejam de cunho acadêmico, sejam de cunho político de militância nas ruas: a capacidade de atrair novo integrantes e fazerem-se renovados com suas potências críticas e transformadoras, de novo postas a serviço não só das mulheres, mas da humanidade. 


\title{
Apresentando os resultados: queremos os discursos, não os rótulos
}

\author{
Apresentando as entrevistadas
}

As entrevistas individuais foram realizadas no campus Coração Eucarístico da Pontifícia Universidade Católica de Minas Gerais, em Belo Horizonte, no horário da manhã e com roteiros semi-estruturados, divididos em três blocos: 1 - Dados gerais: levantei informações que julguei relevantes para delinear o perfil das entrevistadas e identificar a homogeneidade ou a heterogeneidade do grupo; 2 - Representações sobre o feminismo: neste bloco, busquei analisar quais representações essas jovens mulheres tinham sobre o feminismo, as mulheres, o feminino, as lutas e as demandas do feminismo, o imaginário delas sobre as feministas e a percepção sobre o gênero, especialmente no que tange às relações assimétricas bem documentadas pela literatura sociológica e antropológica; 3 - Pautas dos movimentos feministas: apresentei algumas e pedi que se posicionassem com base nelas. As pautas escolhidas foram: descriminalização do aborto, maternidade, autonomia, participação política, liberdade sexual e violência contra a mulher.

As quatro entrevistadas foram selecionadas tendo como base o seguinte desenho amostral ${ }^{5}$ : uma feminista declarada (Entrevistada A), uma feminista que não aceitasse o rótulo (Entrevistada B), uma não-feminista com algum discurso feminista (Entrevistada C) e uma não-feminista e sem o conhecimento do discurso feminista (Entrevistada D). Com essa escolha amostral, queria comparar discursos e descobrir quais afinidades e repulsas essas jovens universitárias tinham contra o discurso ou o rótulo: mulher feminista. Queria identificar medos, aproximações, semelhanças, mal-entendidos e conflitos; mas, acima de tudo, significados. Selecio-

\footnotetext{
${ }^{5} \mathrm{O}$ critério para atribuir às entrevistadas rótulos de feminista é o da autorreivindicação, ou seja, se ela se considera ou não uma feminista. Essa era a primeira pergunta do questionário. Dependendo de como ela se caracterizava, o convite para ser entrevistada era realizado e seguiam as próximas perguntas dos questionários conforme especificado acima. Não me ocupei de compreender qual a corrente dentro do feminismo em que a Entrevistada A (única entrevistada que reivindicou a qualificação de feminista) se enquadraria, pois conforme os propósitos deste trabalho, a visão de "o que é o feminismo" seria construída valendo-se de como ela se apropria do feminismo que conhece e o que ela produz com isso. Quanto às outras entrevistadas, todas se declararam não-feministas, mas o grau de aproximação com os movimentos sociais feministas locais e os posicionamentos sobre essas pautas me fizeram atribuir o título, de feminista ou não, pela minha própria interpretação sobre os discursos delas. Assim, a Entrevistada B tinha uma aproximação com os eventos políticos da cidade de cunho feminista e uma quase que completa aceitação de todas as demandas elencadas, por isso, a qualifiquei como feminista, ainda que ela pessoalmente não se sentisse à vontade com esse rótulo. Mais tarde, conclui que a não aceitação do rótulo se dá pela sua escassez de informações sobre o feminismo.
} 
nei essas meninas com base em certa conveniência e em alguns conhecimentos prévios sobre elas.

\section{Interpretando discursos}

As entrevistadas entendem o feminismo como um movimento social e uma luta. Trata-se de um espaço político de discutir direitos e deveres, mas, principalmente, de produzir mudanças. Que tipo de mudanças? Três das quatro entrevistadas acreditam que os objetivos do feminismo sejam a construção de uma sociedade onde o jogo do machismo se inverta e o que tenhamos é a superioridade feminina. Somente a Entrevistada A conceituou o feminismo como a luta pela igualdade entre homens e mulheres. Existe, evidentemente, esse feminismo "mais radical", mas a maior parte dos grupos feministas que conheço em Belo Horizonte não compartilha dessa necessidade de sobreposição feminina e concentra seus esforços na luta pela igualdade entre homens e mulheres. Quando questionadas sobre o que era ser mulher, as respostas partiam de um esquema mais biologicista de conceituação, como salienta a Entrevistada D: "Ser mulher pra mim é uma questão de sexo, eu nasci mulher".

Quanto à definição da Entrevistada A, conceituar o "ser mulher" só é possível dentro de uma perspectiva construtivista e, portanto, não ancorada a biologicismos e a essencialismos: "Na verdade, em cada sociedade, em cada país, em cada época, ser mulher é diferente, e acho que também ser mulher, no meu ponto de vista, é desconstruir um pouco dessas coisas, assim. Um pouco dessas imagens préestabelecidas e pensar que a mulher pode ser o que ela quiser".

As outras duas entrevistadas trabalham com um critério mais comportamental de conceituação. Assim, o critério para a definição do que é ser mulher, vem de um comportamento de guerreira, incansável, pronta para uma batalha. E qual seria essa batalha? Pelas respostas fica claro: vencer uma dupla, tripla, quádrupla jornada e cumprir vários papéis sociais ao mesmo tempo; ou outro critério que vem do comportamento de cuidadora, mais clássico, ligado ao lar e ao universo doméstico, das relações do cuidado, sensíveis e íntimas. 
Pra mim, é ser guerreira demais. Ser... é tão difícil definir, mas é. É uma constante batalha ser mulher... (Entrevistada B).

Ser mulher é não parar nunca. Ser mulher é cada dia se deparar com uma dificuldade diferente e arranjar maneiras de enfrentar aquilo. Ser mulher é lutar pelas pessoas que a gente ama e defender quem a gente ama com unhas e dentes. Ser mulher é ser a casa de alguém... (Entrevistada $\mathrm{C}$ ).

[...] que, pra mim, ser mulher é a gente ter um jeito muito diferente de tratar as relações humanas, as relações sociais, não porque a gente é um ser de outro mundo, mas porque a gente foi inclusive socializada de maneira muito diferente, então eu acho que as mulheres têm o principio da solidariedade muito mais forte que os homens, eu acho que a gente exerce a nossa solidariedade no nosso dia a dia, eu acho que como sempre estivemos associadas às atividades do cuidado, cuidar dos filhos, dos idosos, da casa, então a gente tem essa coisa de pensar nos outros, pensar no cuidado dos outros, isso também é algo que foi construído como ser mulher (Entrevistada A).

Não fica claro o que é ser feminina, e nota-se, muito claramente, que essa relação entre mulher e feminilidade está em conflito. Se cuidar, ter vaidade não é mais critério absoluto, isso nos leva à segunda questão, pois ser feminina demais parece conferir à mulher uma fragilidade que pode dar margem à discriminação e ao descrédito por parte dos outros. Assim, todas elas concordam com a existência da discriminação - ainda que só duas pessoalmente tenham se considerado vitimas dela, as entrevistadas A e B - e atrelam sua existência à presunção de uma incapacidade ou fragilidade que as mulheres parecem ter de contornar. Elas assim rejeitam o rótulo de feminilidade a ponto de poderem usar atributos culturalmente associados aos homens (poder de decisão, liderança, segurança, firmeza no agir, etc.), mas sem entrar no reino das "masculinizadas" que as descaracterizaria e colocaria em risco seu estatuto de mulher.

[...] e o feminino, tem muito a ver com essa construção do que é ser mulher e do que é ser feminino. Eu não gosto inclusive da palavra feminino, eu acho que dá muito a idéia de que a mulher tem de ser delicada, tem de ser preocupada com a vaidade, ela tem de estar dentro dos padrões de beleza, e eu num acho que isso é ser mulher, assim (Entrevistada A).

[...] e ser feminina, sinceramente, eu num consigo te dar uma definição do que é ser feminina. Porque eu mesma tenho um conflito com isso. De quando eu sou e quando eu não sou feminina. Ser mulher pra mim já é ser feminina (Entrevistada B).

Ser feminina para mim é se cuidar. É o cuidar, em geral (Entrevistada C).

Todas as entrevistadas se pensam como mulheres decididas e sentem muito orgulho da sua capacidade de realização, sua independência, e, nesse contexto, a 
discriminação contra as mulheres torna-se algo bastante difuso, vago, e direcionado à ameaça do não-reconhecimento de sua independência, de sua liberdade de expressão, do direito a frequentar certos espaços (incluindo prescrições de comportamento em espaços garantidos a ambos os sexos) e da sua competência.

Existe discriminação demais, já sofri. Desde sentar em um boteco pra falar de futebol até dentro de uma sala de aula pra falar de política. Várias coisas, frequentar certos lugares, estar em certos lugares que são lugares masculinos. Ou até mesmo estar em lugares que são para ambos os gêneros, mas com uma postura diferente da maioria das mulheres, ou pelo menos do que é ditado como uma postura feminina pelo senso comum (Entrevistada B).

Eu num sei se posso chamar de discriminação, acho que num foi discriminação em si, é mais machismo mesmo, não discriminação. De homens que eu já tive, de achar que só porque eu sou mulher, eu sou uma bonequinha de louça, que eu num posso fazer nada, que eu num posso resolver nada, que eles que têm de ficar no controle de tudo, e isso me irrita. Só porque é mulher, tem de deixar os outros fazerem por elas? Num existe isso não (Entrevistada C).

Particularmente interessante é a resposta da Entrevistada D, que não se reconhece como feminista nem sustenta as demandas políticas das feministas, em cujas ideias ela reconhece a existência da discriminação, mas não se sente tocada por ela.

Eu acho que existe sim [discriminação contra as mulheres], principalmente por questão de salário, que até hoje a mulher tem o mesmo cargo que o homem e recebe um salário abaixo, em muitos casos. Eu nunca sofri nenhuma atitude discriminatória não (Entrevistada D).

A discriminação só fica mais clara no mundo do trabalho, e todas as entrevistadas citaram questões salariais e o sistema capitalista para ilustrar a opressão em relação às mulheres.

Eu acho que a discriminação vem no âmbito do trabalho, tanto no trabalho formal, em que as mulheres ganham menos que os homens, quanto no trabalho doméstico, que é exercido majoritariamente pelas mulheres, colocado como algo invisível. É o papel natural das mulheres fazer o trabalho doméstico. E, esse trabalho, ele tem um custo na sociedade, ou seja, o capitalismo se aproveita da invisibilização do trabalho doméstico e, por exemplo, sabendo que têm as mulheres pra lavar o uniforme dos seus empregados, uma fábrica vai deixar de fazer isso dentro dela, o que geraria um custo, lavar os uniformes dos seus empregados, que passa pra dentro da família, pra dentro da vida das mulheres e dilui esse custo, ou seja, as mulheres fazem isso de graça. Então, o capitalismo tá baseado nessa opressão do trabalho, mas não acho que é só nesse domínio, acho que na própria sexualidade, na própria relação com o corpo, muitas vezes o prazer sexual das mulheres tá vinculado ao prazer do homem, temos poucas oportunidades de ver que podemos ter o prazer por nós mesmas, assim, o prazer sexual está 
sempre colocado com relação ao outro, assim, você vê essas revistas femininas: Mil maneiras de enlouquecer um homem na cama! Ué, e as mil maneiras de enlouquecer a mulher? E as maneiras que a gente tem pra ter um prazer sexual? Então, isso não é falado. No trabalho, na sexualidade, em vários outros espaços da vida, eu mesma já sofri, acho que todas as mulheres já sofreram alguma discriminação, alguma opressão e algumas delas não conseguem colocar isso na palavra de opressão, mas sabem que isso é um incômodo. Quando a gente, por exemplo na política, eu faço parte de um grupo político, de partido, e muitas vezes o que a gente fala é menos ouvido do que o que um homem fala, e isso em vários outros movimentos, em que acontece a mesma coisa (Entrevistada A).

Com relação ao imaginário sobre as feministas, pedi que elas descrevessem uma feminista, como elas imaginavam, como se comportaria e seria. 0 que obtive foi um desenho que não remete a uma imagem, mas a um modo de se comportar e de ser: uma feminista é uma mulher forte, polêmica e que não abaixa a cabeça para ninguém. Elas reconhecem que uma feminista pode estar misturada no meio de outras, usando lilás ou não, vaidosa ou não, mas o que denunciaria essa militante seria a força e a coragem para emitir opiniões e se colocar contra o machismo.

Nossa, pode ser uma coisa super estereotipada, provavelmente é na verdade, porque eu não conheço pessoalmente nenhuma feminista. Mas o que eu acho na minha ignorância é que uma mulher feminista é uma mulher que não abaixa a cabeça pra homem nenhum, que trata homem como um ser inferior. Como ela se veste? Como uma mulher normal, num sei, eu acho que sempre a feminista é uma mulher de negócios, bem sucedida, que pisa na cabeça dos homens de salto alto. Ela fala com um tom de autoridade e segurança por ser quem é, com orgulho de ser mulher (Entrevistada C).

Então, a imagem que vem pra mim de feminista... Primeiro, as feministas usam sempre lilás. Que o lilás é a cor do feminismo, essa cor foi incluída no feminismo nos anos 70, na segunda onda do feminismo, que era a junção do azul e do rosa, que aí tinha a ideia de construir uma nova mulher e um novo homem. 0 lilás faz muito parte da nossa identidade, você então vai reconhecer uma feminista porque muita coisa dela é lilás. Segunda coisa é porque não necessariamente tem os padrões rígidos de beleza na sua identidade, mas não quer dizer que queremos ser feias. A gente acha que é bonito ser bonita, mas a gente só num vai gastar muito tempo fazendo isso, por que a gente precisa lutar pelos nossos direitos. Então, se a gente ficar sábado o dia inteiro na manicure, no salão de beleza, a gente num vai ter tempo pra militar, já que a gente tem uma jornada de trabalho muito extensiva; então as mulheres são tão arrumadas quanto às outras, mas com esse sentido de a beleza ter outro significado. E acho que são mulheres que não levam desaforo pra casa. Elas fazem questão de dizer quando sentem alguma situação, algum incômodo, alguma opressão e, com certeza, vão colocar os seus direitos. Muitas vezes, elas são bem reconhecidas pelas pessoas em volta porque são polêmicas (Entrevistada A).

É como eu lhe disse antes, acho que tem vários tipos de feministas, vários tipos de mulheres. Eu acho que ela se veste como uma mulher, mas com uma postura de força, o que eu acho que todas as mulheres deveriam ter. É ter uma postura forte, apaixonada até, às vezes. Mas não acho que ela queira, que ela seja, tão diferente de uma mulher que não se considere feminista. Acho que ela é uma mulher, igual todas as outras, mas que luta por uma causa que ela acredita. Igual uma militante do MST, uma modelo que 
quer ser Top Model. Mas acho que ela tem uma peculiaridade, que é ela, muitas vezes, ter que ter uma postura defensiva, não porque ela quer, mas porque ela sabe de tudo que ela vai ter de enfrentar, então isso faz com que ela tenha essa postura mais defensiva diante das pessoas, principalmente perante os homens (Entrevistada B; grifos do autor).

Chama-me a atenção esse lugar de conhecimento, de consciência, que é atribuído às feministas. Em dados momentos, aparece como uma lucidez com relação às condições femininas e, por vezes, como um exagero.

Somente a Entrevistada A, declaradamente feminista e militante, julga-se uma feminista, ainda que todas as entrevistadas, em várias medidas, sejam mulheres que acreditem na necessidade da igualdade entre os sexos. 0 medo, ao que parece, vem das posturas extremistas, de modo que, mesmo sendo os discursos amplamente conhecidos e admirados por todas elas, o que elas rejeitam é o rotulo de feminista. Não ficou claro para mim nenhum outro motivo para a rejeição em se identificar com o feminismo, além do desconhecimento do que é mesmo ser feminista e o medo de cair em radicalismo extremado (a que se relativizar o que seria uma posição feminista razoável e uma posição feminista extremada, e isso, a meu ver, tem grandes ligações com aspectos como filiação política, teórica e o lugar em que a pessoa avaliadora ocupa no sistema de estratificação social).

Os maiores desafios para as mulheres hoje, segundo minhas entrevistadas, são bastante variados, como: conquista da igualdade entre os sexos, saber conciliar com qualidade trabalho/estudo/cuidado doméstico/relacionamentos pessoais, conseguir que os direitos das mulheres sejam respeitados, assim como a positivação do que é ser mulher na vida em sociedade e ocupar espaços até então interditados a elas.

[...] ser mulher é complicado, e desafio de mulher é cuidar da casa, conciliar casa com trabalho, família, viagem. E acho que é isso, acho que nem é uma luta contra o preconceito, mas acho que é mais conciliar isso tudo. Porque eu acho que mulher é mais aquela que abraça tudo assim, tem aquela coisa de cuidar. 0 trabalho com paixão, a casa com paixão, cuidar dos filhos com paixão, então isso que é difícil de conciliar (Entrevistada $\mathrm{C}$ ).

Eu acho que é no sentido de saber conciliar o emprego com a família, essas lutas que sempre vêm acontecendo, pela igualdade mesmo. Porque eu acho que a luta das feministas é por querer ser superior, acho que num devem ser assim. É tratamento igual. Eu sou mulher, mas eu tenho direitos, que devem ser iguais (Entrevistada D). 
Uma resposta que me instigou muito foi a posição contraditória da Entrevistada B, que, apesar de reconhecer anteriormente que o feminino não é tão fácil de ser delineado, sente que este é um direito da mulher, que deve ser preservado de alguma forma, como um direito à diferença. Parece-me que, para ela, o direito à diferença seria um posicionamento conflitante com a noção de igualdade entre os sexos, como se a igualdade acabasse por abolir a diferença e esta fosse uma perda para mulheres e homens, e, talvez, seja essa confusão entre isonomia e homogeneização que provoque a sua aversão aos movimentos feministas.

[...] eu acho que o maior desafio é a mulher lutar pela sua igualdade, pelo que ela quer, sem deixar de lado sua diferença. 0 que eu acho que é um cuidado que todas as mulheres têm que ter. Porque nós ficamos querendo muito lutar pela nossa igualdade, pelos nossos diretos, mas não podemos esquecer que somos mulheres e os homens são homens, e que nós somos seres diferentes. E é preciso muito cuidado para que não percamos isso. Não perder a nossa diferença e as nossas características, e qualidades e defeitos que são femininos e não masculinos. Pra gente não se tornar homens de calcinha (Entrevistada B).

Tentei também delinear os papéis de gênero que as entrevistadas teriam em mente para homens e mulheres, mas a maior parte delas acredita que seja possível que a mulher esteja em todos os espaços e realmente possa fazer tudo hoje em dia. Porém, fica claro que o cuidado doméstico, a maternidade e a sensibilidade sempre serão prerrogativas femininas, e que existe uma limitação clara entre o universo das mulheres e o dos homens.

Sendo feminista, fica muito difícil pra mim definir o que é coisa de mulher e o que é coisa de homem. 0 que antes era só coisa de homem já foi ocupado pelas mulheres, como o voto, que nós tivemos aí, tardiamente, que era uma coisa de homem e, hoje, é uma coisa que as mulheres também participam. A política, que muitas vezes era colocada como coisa de homem, e hoje a gente já ocupa, mesmo de maneira aquém do que gostaríamos. Eu acho que coisa de homem e coisa de mulher geralmente reproduz essa separação entre o público e o privado. As mulheres sempre foram relegadas ao privado, que é essa coisa do cuidado com os filhos, com o lar, com o marido, etc. E o homem foi colocado no público, que é o âmbito da política, dos direitos, da participação, da produção. Eu acho então que coisa de mulher é tudo, e coisa de homem é tudo também (Entrevistada A).

Coisas de mulher: ficar grávida, amamentar, depilar. Ter que saber como se portar nos lugares e ter que ter cuidado com suas ações e posturas e falas. 0 que eu acho que não tem esse tipo de pressão sobre o homem, que é ter de saber como e quando fazer. E ser mãe, que é uma coisa bem da mulher mesmo. Que ser mãe é um espaço que o homem nunca vai ocupar. Agora, ser homem, é...eu acho que homem sofre um bocado também, né? Porque o homem também tem os seus estigmas, né? Também sofre preconceito, principalmente por parte dos próprios homens. Então, ser homem é ser du- 
rão, é ter voz grossa, acho que na nossa sociedade, no meio urbano, é ter um bom emprego, um bom carro, uma mulher, né? Uns filhos legais, e mesmo assim continuar sendo um garanhão e arrasar os corações por aí. Acho que é isso, eu num sei por que eu num sou homem, e é muito difícil falar, mas eu enxergo dessa forma (Entrevistada B).

Cuidar da casa é coisa de mulher... É mais por consequência do que por ser genuinamente coisa de mulher, apesar de que, desde os primórdios, é assim, mas, apesar disso, não existe isso não, coisa de mulher, coisa de homem. Cada um tem as suas coisas, independentes de ser mulher ou de ser homem, tem homem que cuida de casa, é menos recorrente, mas tem (Entrevistada C).

\section{As pautas feministas}

Todas as mulheres entrevistadas são a favor da descriminalização do aborto e entendem que isso é um problema de saúde pública que vitimiza muitas mulheres (especialmente as de baixa renda) e com a descriminalização, essa questão seria tratada de forma mais humanizada e menos dramática.

Eu sou super a favor cara! Sou a favor da legalização, eu acho que acontece, é recorrente. A gente vê, aí, mãe abandonando bebês na lagoa, mãe matando filho, espancando, tratando mal; criança sendo levada pro conselho tutelar porque a mãe num para em casa, porque num quer... criança abandonada é o que a gente mais vê. E isso é um absurdo, porque tem gente que fala: é vida! Tem de deixar! Aí a criança cresce num lar que num é querida, que num tem suporte, vai pra rua, sem cuidado, sem amparo. Eu acho que isso aí num resolve nada não, olha a vida que você escolheu pra dar pra criança. Eu acho isso uma puta sacanagem (Entrevistada C).

Em partes, eu concordo com o aborto, em situação como gravidez de menores e quando a pessoa não tem realmente condições de criar essa criança. É uma questão moral e de saúde pública, mas não religiosa. Com a legalização, muita coisa que é feita na ilegalidade poderia se tornar legal, e haveria, eu vejo como uma possibilidade, a redução do aborto. Se o governo tivesse uma preocupação em relação a isso, as pessoas teriam mais informações e saberiam como agir nessas situações. Como não tem uma posição do Estado sobre isso, acabam muitas coisas acontecendo, por conta da ilegalidade (Entrevistada D).

As Entrevistadas A e B partilharam de opiniões quase idênticas sobre a descriminalização do aborto, inclusive destacando quase os mesmos pontos, o que reforça a minha categorização de que ambas são feministas, ainda que a entrevistada B não aceite o uso do rótulo.

Eu sou completamente favorável à legalização do aborto. É importante dizer que nenhuma mulher é favorável ao aborto, porque, muitas vezes, essa decisão é difícil, é sofrida, ela envolve outros sofrimentos que a mulher está passando naquele momento, e pra mulher nenhuma é fácil tomar essa decisão, mas quando elas tomam, é porque elas não querem ter uma gravidez. Uma gravidez indesejada é algo muito terrível pra uma mulher. Então, eu sou a favor da legalização do aborto, o que significa que a gente 
tenha um aborto seguro e, principalmente, oferecido pelo sistema público de saúde. Hoje, as mulheres que têm dinheiro abortam nos níveis bons de higiene e saúde, e as mulheres pobres utilizam os meios mais precários, difíceis pra própria saúde delas. Inclusive, eu acho que é isso assim, as mulheres pobres e negras são as que mais morrem por um aborto ilegal e a gente tem o dado de que, no SUS, a internação por curetagem do útero, o procedimento que se faz depois de um aborto, seja ele induzido ou não, tá superando outras formas de internação para a saúde da mulher, é isso, então, um problema de saúde pública. Nós do movimento feminista acreditamos que num é só um problema de saúde pública, porque achamos que também somos nós que temos de decidir sobre o nosso corpo. Não é Estado, não são os homens, não são os juízes, não são os papas, mas sim as mulheres. Porque a gente tem uma coisa bem polêmica, que é uma frase: 'se o papa fosse mulher o aborto não seria ilegal.' No sentido de que quando são pras mulheres, as coisas são sempre mais difíceis de se conseguir, tem muita mais dificuldade de ser aceita (Entrevistada A)

Eu sou a favor da legalização do aborto, acho que é uma questão de saúde pública. Acho que cada um tem a sua religião, cada um tem a sua moral, então é muito difícil você ditar através de moral, religião, o que a mulher pode ou não pode fazer com o seu próprio corpo. Mas eu acho que nenhuma mulher aborta porque ela acha legal, porque ela quer abortar, ninguém acha legal abortar. Só que a mulher sabe da sua realidade, sabe do seu corpo, sabe do que ela quer e do que ela num quer, então ela tem de ter autonomia sim pra fazer isso. Até porque eu acho que é uma coisa de classe social, pois uma pessoa que é de uma classe social mais alta tem acesso a clinicas de aborto. Ela faz o aborto com toda segurança de que num vai acontecer nada com ela, de que ela vai ficar bem, e realmente num acontece nada, ela fica bem. Mas uma pessoa que é de uma classe mais baixa, ela num tem como pagar uma clínica dessa pra abortar, então ela vai pros meios caseiros, que a gente sabe, chá, remédios, essas coisas que causam o aborto e ela tá correndo risco e o filho dela também tá correndo o risco do aborto não acontecer e ele nascer com sequelas, né? Então vem a religião e dita que o aborto é proibido e tal, mas o que entendo é, mais uma vez na história das humanidades, os pobres têm que pagar pelos ricos, então eu acho que a religião é um tanto quanto hipócrita nessa questão assim. Isso tem de ser uma escolha dela, porque elas sabe como as coisas acontecem. Mas eu sou a favor e acho que a mulher tem de ter autonomia sobre o corpo dela sim (Entrevistada B).

Quanto ao modo de encarar a maternidade, as entrevistadas entendem essa experiência como algo muito rico e com significado bastante profundo, mas que deve ser partilhado por ambos os responsáveis pela criança, independente do sexo. Fica claro que o problema não é a maternidade na vida das mulheres, mas a obrigatoriedade dela - que pode ser uma pesada imposição social - e o desamparo por parte do parceiro, acreditando que as tarefas envolvendo a criança devem ser legadas à mãe. Elas colocam-se na posição clara de querer a maior participação masculina na parentalidade, mesmo reconhecendo que não é muito comum que isso ocorra. É importante notar que ser mãe não é um requisito para a completude feminina para a maior parte das entrevistadas, mas todas elas, em certa medida, concordam que se trata de algo bem típico do universo feminino, e, de certa maneira, até mesmo um dom, ou um privilégio concedido à mulher. 
Ser mãe, pra mim, é ser a casa de alguém. É ser o mundo, só que deixando o menino crescer e viver a própria vida. É ser a referência de caráter, a referência de vida assim, pra tudo. Mãe dá de mamar, né cara? Pare. Mas eu acho que a responsabilidade é igual, as funções são diferentes. No início, tem a gestação, isso aí é diferente, isso aí pai não tem como ajudar, mas eu acho que tem coisas que o pai pode tomar pra fazer sim, tanto quanto a mulher. E eu acho até muito bonitinho quando o homem se dispõe a ajudar, e tem facilidade maior com os filhos, e toma a responsabilidade pra si, eu acho legal. Por que é igual pra todo mundo. Só que tem pais que acham que porque é mulher, é mãe, ela que cuida. Mas num tem nada disso não. Pra mim é tudo igual (Entrevistada C).

Quando discutido temas relativos à autonomia, ou seja, à capacidade ou à liberdade de agir, de falar e de ser de cada sujeito, as mulheres entrevistadas colocam-se todas como mulheres de opinião, mas que entendem como importante consultar outras pessoas antes de agir, seja por prudência, seja por respeito, mas todas se veem, por vezes, como autoritárias e cheias de vontade. Principalmente nos relacionamentos, em que revelaram ter certa tendência para monopolizar as decisões. Os homens, no entanto, pela avaliação das entrevistadas, gozam de muito mais liberdade de agir e falar do que qualquer mulher. Elas entendem isso como uma séria frustração para a interação social, sendo a maior parte das entrevistadas bastante críticas à essa hegemonia do masculino na interação social.

Ao serem provocadas para discutir o tema da participação política, elas confessaram imaginar homens no poder, e entendem que esse é um domínio masculino. Entretanto, veem com bons olhos a ocupação feminina nesses espaços, não porque uma mulher é mais representativa, mas por entender que não há nenhum empecilho para a participação feminina na política. Todavia, somente as duas entrevistadas com maior conhecimento sobre o feminismo fazem questão de participar de eleições e engajar-se politicamente em alguma causa. Isso para mim é um forte indício de que o feminismo é um estágio de politização e, como tal, educativo para a vida cidadã.

No quesito liberdade sexual, as entrevistadas exibem uma postura mais libertária com relação ao sexo e reivindicam tanto a liberdade de gozar da sua sexualidade e de fruir da própria sensualidade, quanto a necessidade de se sentir satisfeita (em todos os sentidos) num relacionamento. Elas ressaltam que a liberdade masculina é bem maior, e reclamam do moralismo em torno da mulher e da vigília social que se exerce sobre ela ao se empregarem rótulos como "santas" e "putas". A 
mulher deve procurar se enquadrar num dos dois, e, sendo uma ou outra, acabam como alvos de algum tipo de discurso machista que espolia o direito à posse e expressão de sua sexualidade.

A violência contra a mulher, por sua vez, foi declarada por duas entrevistadas, e a entrevistada feminista mencionou a violência psicológica. As mulheres que costumam sofrer violência física, sofrem caladas, geralmente por vergonha, medo ou baixa autoestima, o que acaba agravando muito esses casos. Caracterizar a violência é outra coisa muito complexa, assim como tomar consciência quando se é vitima desse tipo de assédio violento. A violência contra a mulher assume muitas formas, desde ataques à autoestima, até assédio sexual, sempre pelo simples fato de ser mulher e a masculinidade autorizar essas invasões. Todas as entrevistadas conhecem a Lei Maria da Penha ${ }^{6}$ e compreendem que ela é de suma importância para que a segurança e integridade das mulheres sejam respeitadas, e, apesar de todas as suas falhas e polêmicas, é uma medida essencial para corrigir um erro histórico, que Simone de Beauvoir qualifica como "o grande Outro da história da humanidade", a maior e mais vitimada minoria do mundo: as mulheres.

\section{Conclusão}

O que me parece claro é que o discurso feminista está totalmente diluído nas mais diversas áreas da vida social, de forma que, tanto mulheres mais engajadas na luta pelos direitos delas, quanto aquelas que não se identificam com o rótulo de feminista, utilizam-no e reconhecem sua lucidez e importância para suas vidas. Concluo propondo que existem escalas de uso das qualificações feministas, como de conhecimento e adesão às bandeiras desse movimento, mas que essa escala não é suficiente para determinar o posicionamento em relação às pautas femi-

\footnotetext{
${ }^{6}$ A Lei Maria da Penha é a matéria legal vigente que trata os casos de violência contra a mulher e determina providências a esse respeito, no sentido de garantir os princípios da dignidade humana e a proteção legal para as vítimas da violência doméstica, reconhecendo as especificidades das mulheres nesse tipo de violência que ocorrem desde graus sutis até os mais trágicos em todo território nacional. 0 processo de consolidação dessa lei dá-se desde o momento da criação da primeira delegacia da mulher, em 1985; o do surgimento dos Juizados Especiais Criminais, em 1995; e o da promulgação da Lei 11.340, em 2006, conhecida como Lei Maria da Penha. Para maiores detalhes, indico o texto Da delegacia da mulher à Lei Maria da Penha: Absorção/tradução de demandas feministas pelo Estado, de Cecília Macdowell Santos. Disponível em: <http://www.ces.uc.pt/ ficheiros2/files/gender\%20workshopRCCS 89 Cecilia Santos.pdf>.
} 
nistas. Com isso, quero dizer que o quanto de feminismo que as mulheres conhecem não necessariamente determina a sua aprovação às pautas do feminismo. Entretanto, o grau de conhecimento do feminismo determina, ao meu ver, o nível de participação política, de engajamento em causas de luta pelos direitos das mulheres, e, principalmente, o grau de consciência sobre as possibilidades de opressão que o machismo e o patriarcado colocam, de forma muitas vezes sutil e perversa, na vida de todas as mulheres.

Como se sabe, as conquistas políticas e sociais que existem para as mulheres, na atualidade, vêm de um longo passado de associação, organização e atuação política de mulheres que entendiam ser a realidade marcada por contextos patriarcais que atendem a uma ordem iminentemente capitalista e heterossexista. Essas conquistas só podem ser mantidas e ampliadas se forem abraçadas por todos e sustentadas nos campos de atuação dos atores políticos, levadas em bandeiras de movimentos sociais, organizações e coletivos de pessoas dispostas a derrubar as barreiras que ainda insistem em permanecer no nosso cotidiano (muitas vezes naturalizadas e mascaradas em disfarces sutis e perversos). Assim sendo, ter uma consciência feminista possibilita ter maior conhecimento das formas que as mulheres podem ser oprimidas, assim como das maneiras de agir e de se posicionar para alcançar seus direitos.

\section{Referências}

AlvARES, C. (1992). "Feminismo e representação discursiva sobre o feminino: a presença do outro na teoria e na prática”. In: _. As mulheres e a mídia. Lisboa, SopCOM.

BonetTI, A. L. (2009). "Etnografia, Gênero e Poder: Antropologia Feminista em Ação". Dossiê: Contribuições do pensamento feminista para as ciências sociais. Revista Mediações. Londrina, vol 14, dez.

CARneiro, S. (2001). "Enegrecer o Feminismo: A situação da Mulher Negra na América Latina a partir de Uma Perspectiva de Gênero". Lola Press. Novembro, n. 16. Disponível em: <http://www.bibliotecafeminista.org.br/index.php?option=com remository\&Itemid=53\&func=startdown\&id=208 $>$. Acesso em jun. 2011.

Faria, N. (2007). "Perspectivas Feministas de Diversidade Sexual”. Revista America Latina em Movimento: Sexualidades Dissidentes. Maio. Disponível em: <http:// www.sof.org.br/publica/pdf ff/65.pdf>. Acesso em jun. 2011.

Flick, U. (2002). "Entrevista episódica”. In: BAuER, M. W.; GASKELL, G. (Org.). Pesquisa qualitativa com texto, imagem e som: um manual prático. Petrópolis, Vozes. 
Horochovski, M. T. H. (2004). "Representações Sociais: Delineamentos de uma Categoria Analítica”. Em Tese. Florianópolis, vol. 2, n. 1 (2), janeiro-junho, p. 92-106. Disponível em: <http://www.emtese.ufsc.br/2 art7.pdf $>$. Acesso em jun. 2011.

LOPEs, M. M. (2002). “As grandes ausentes das inovações em Ciência e Tecnologia”. Cadernos Pagu. Campinas, n. 19, p. 315-318. Disponível em: <http://www.scielo.br Lscielo.php?script=sci arttext\&pid=S0104-83332002000200012\&lng=en\&nrm= iso $>$. Acesso em jun. 2011.

NAvarRo, M. H. (2009). "Entre o acadêmico e o popular: os rumos do feminismo atual”. Revista Estudos Feministas. Florianópolis, janeiro/abril, vol 17.

Отто, С. (2004). “O feminismo no Brasil: suas múltiplas faces”. Revista Estudos Feministas. Florianópolis, agosto, v. 12, n. 2. Disponível em : <http://www.scielo.br/ scielo.php?script=sci arttext\&pid=S0104-026X2004000200015\&lng=en\&nrm= iso $>$. Acesso em jun. 2011.

ScoTT, J. (1996). Gênero: uma categoria útil para a análise histórica. Recife, SOS Corpo.

ZANETTI, J. P. (2008). “Jovens Feministas: um estudo sobre a participação juvenil no feminismo". Revista Fazendo Gênero. Florianópolis, n. 8.

Recebido em março/2011

Aprovado em julho/2011 


\title{
$\underline{\text { Anexo }}$
}

\section{Roteiro de Entrevistas de "Mulheres ilhadas: representações do feminismo na perspectiva de jovens mulheres universitárias"}

\author{
I Bloco - Dados Gerais \\ Idade: \\ Identidade racial: \\ Local de nascimento/moradia:
}

Religião:

Renda (familiar/ pessoal):

Onde passou a maior parte da vida (cidade ou interior):

\section{Bloco - Representações sobre o feminismo:}

1 - 0 que é o feminismo, na sua opinião?

2 - 0 que é ser mulher? 0 que é ser feminina?

3 - Existe discriminação contra a mulher hoje? Já sofreu alguma discriminação? Como foi?

4 - Descreva uma feminista? Como ela é? Como se veste? Como se comporta? 0 que ela faz?

5 - Você se considera uma mulher feminista? Por quê?

6 - Quais são os desafios das mulheres hoje?

7 - 0 que é coisa de mulher e o que é coisa de homem?

\section{Bloco - Pautas feministas}

\section{Aborto}

1 - Qual é a sua posição sobre a legalização do Aborto? É uma questão moral, de saúde pública, religiosa? 


\section{Maternidade}

2 - 0 que é ser mãe para você? As responsabilidades da mãe são maiores que as do pai?

3 - 0 que acha da seguinte afirmação: "Ser mãe é o sonho de toda mulher, pois a mulher só pode ser completa quando se realiza na maternidade"?

\section{Autonomia}

4 - Você se considera uma mulher de opinião?

5 - Você costuma pedir permissão para agir?

6 - 0 que você acha da afirmação: "Os homens têm mais liberdades para falar e agir do que as mulheres"?

7 - Num relacionamento, quem dita as regras: você, ele, ou tudo é negociado com igualdade?

\section{Participação política}

8 - Quando pensa em alguém num cargo da presidência, do senado, da prefeitura, como é essa pessoa? Me descreva essa pessoa fisicamente e como ela se comporta.

9 - 0 que você acha das mulheres entrando na política?

10 - Você vota em mulher? Acredita que uma mulher possa lhe representar melhor do que um homem? Por quê?

11 - Você participa ou já pensou em participar de alguma atividade política?Por quê?

\section{Liberdade Sexual}

12 - Você acha que a mulher na sociedade brasileira goza da mesma liberdade sexual que os homens?

13 - 0 que você acha das mulheres que exibem de forma mais clara sua sensualidade? E as que não gostam de apostar nisso?

14 - Sentir-se satisfeita sexualmente e/ou afetivamente é importante para você quando esta num relacionamento?

\section{Violência contra a mulher}

15 - Você já vivenciou violência contra a mulher?

16 - Você conhece a Lei Maria da Penha? 0 que você acha dela?

17 - Casos como a da menina Eloá, assassinada pelo ex namorado em SP, acontecem por qual motivo, na sua opinião? 